\title{
Total parathyroidectomy with trace amounts of parathyroid tissue autotransplantation as the treatment of choice for secondary hyperparathyroidism: a single-center experience
}

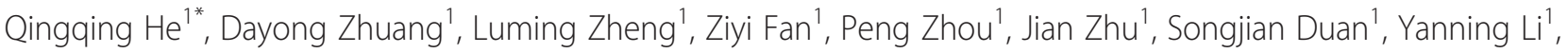
Yanming $\mathrm{Ge}^{2}$, Zhen Lv and Lei CaO ${ }^{1}$

\begin{abstract}
Background: The aim of the study was to evaluate total parathyroidectomy with trace amounts of parathyroid tissue (30 mg) as a surgical option in secondary hyperparathyroidism (sHPT) treatment.

Methods: From January 2008 to March 2012, 47 patients underwent parathyroidectomy. Comparisons of demographic data, symptoms, and preoperative or postoperative biochemistry were made between total parathyroidectomy with trace amounts of parathyroid tissue autotransplantation group and total parathyroidectomy group.

Results: Out of 47 cases, 45 had successful operation. 187 parathyroid glands identified at the initial operation were reported in 47 patients. 43 patients had been diagnosed with parathyroid hyperplasia, and 4 patients had a benign adenoma. After operation, pruritus, bone pain and muscle weakness disappeared, also serum PTH and serum phosphate were declined markedly as well. After discharge, two patients (in total parathyroidectomy group) were readmitted because of postoperative hypoparathyroidism. Graft-dependent recurrence was not observed in an average follow-up of 42 months.
\end{abstract}

Conclusions: Total parathyroidectomy with sternocleidomastoid muscle trace amounts of parathyroid tissue autotransplantation is considered to be a feasible, safe and effective surgical option for the patients with sHPT.

Keywords: Secondary hyperparathyroidism, Chronic renal failure, Total parathyroidectomy, Parathyroid hormone, Autotransplantation

\section{Background}

SHPT is ubiquitous in patients with chronic kidney failure treated by long-term dialysis. High parathyroid hormone (PTH) levels can lead to 1) renal osteodystrophy, 2) calciphylaxis, 3) ectopic calcifications, 4) abnormal fat and sugar metabolism, 5) refractory pruritis, and 6) anemia [1-3]. New treatments for sHPT include vitamin D analogues and calcimimetics. When vitamin D analogues and calcimimetics fails, parathyroidectomy becomes necessary. Surgical treatment of sHPT may involve various surgical approaches [3-6]. Surgical options for the treatment of sHPT include

\footnotetext{
* Correspondence: heqingqing@yeah.net

'Department of Thyroid and Breast Surgery, Jinan Military General Hospital of PLA, No.25 Shifan Road, Jinan 250031, People's Republic of China Full list of author information is available at the end of the article
}

total parathyroidectomy, subtotal (3 1/2 gland) parathyroidectomy and total parathyroidectomy with heterotopic autotransplantation. However, surgeons have been debating on the optimal operative management for patients with sHPT, and surgical consensus on the optimal procedure has not been reached [7-10]. The aim of this study is to examine our experience with patients who underwent total parathyroidectomy with or without trace amounts of parathyroid tissue autotransplantation for sHPT.

\section{Methods}

Patient eligibility and study design

We performed a retrospective study of 47 patients with chronic renal failure, who experienced total parathyroidectomy with or without sternocleidomastoid muscle

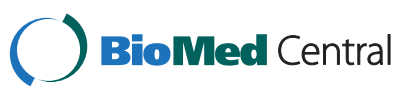

(C) 2014 He et al.; licensee BioMed Central Ltd. This is an Open Access article distributed under the terms of the Creative Commons Attribution License (http://creativecommons.org/licenses/by/2.0), which permits unrestricted use, distribution, and reproduction in any medium, provided the original work is properly credited. 
autografting for sHPT from January 2008 to March 2012. There were 26 men and 21 women and their mean age was 46 years old (range, 28-71). Forty-seven patients underwent hemodialysis for an average of 8.9 years (range 3-19 years). Heights dropped an average of $6 \mathrm{~cm}$ in all patients. After stosstherapy with Calcitriol $2 \mu \mathrm{g}$, twice per week, all symptoms such as pruritus, bony pain, movement disorder, anorexia and kyphosis (Figure 1) were getting progressively worse, with serum PTH and calcium level exceeding the normal range. Our indications for parathyroidectomy in symptomatic patients with SHPT include elevated levels of serum PTH (>1600 ng/L), persistent hypercalcemia, intractable pruritus, osteodystrophy or calciphylaxis, bone pain, and pathological fracture, largesized parathyroid glands (volume $>1.0 \mathrm{~cm}^{3}$ ) on ultrasonography, and/or hyperphosphataemia (>2.26 mmol/L).

Forty-seven sHPT haemodialysis patients provided written informed consent for the study, and the study was approved by the Jinan Military General Hospital Research Ethics Board. The decision to perform total parathyroidectomy with or without autotransplantation was based on a preoperative thorough discussion with the patient. 14 patients chose total parathyroidectomy with trace amounts of parathyroid tissue autotransplantation. 33 patients, not eligible for kidney transplantation, underwent total parathyroidectomy.

\section{Preoperative preparation}

Forty- six patients showed 1-4 radionuclide dense areas in the neck by ${ }^{99}$ Tc-MIBI SPECT scan. All cases had routine preoperative tests including complete blood

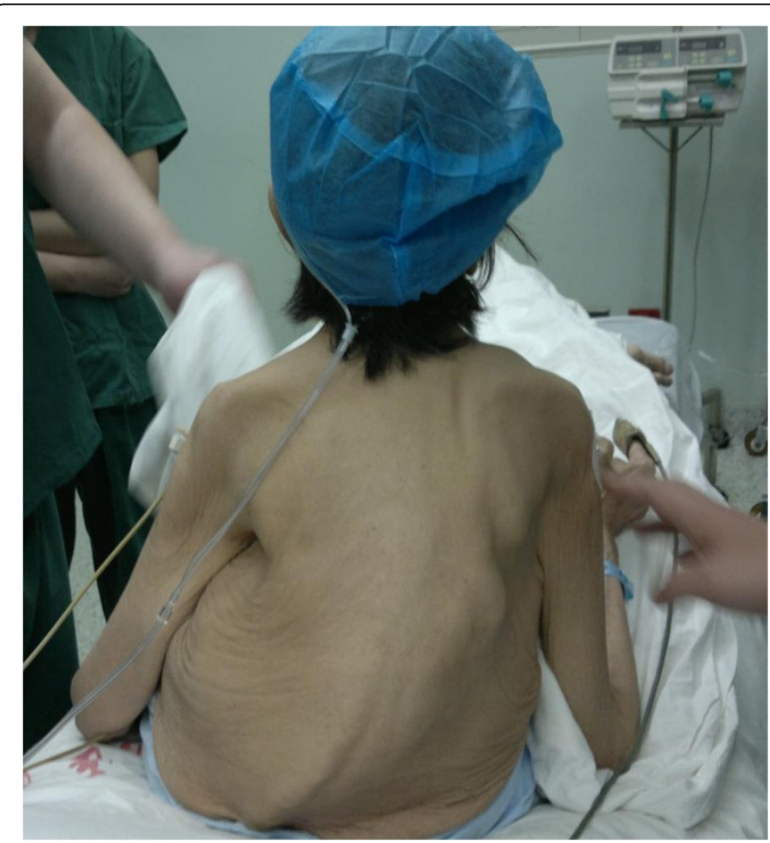

Figure 1 Bone deformities. counts, serum electrolytes, chest $\mathrm{x}$-ray, electrocardiogram, and coagulation screening. Surgical intervention in the form of parathyroidectomy is generally considered only in cases of severe sHPT. However, identification of the exact location of the parathyroid glands before parathyroidectomy is challenging. The surgeon attended the ultrasonography examination, which was helpful to get an exact localization of parathyroid glands (by ultrasonography and scintigraphy) and perspicuous understanding of their relationship with the surrounding tissues. 139 hyperplastic parathyroid glands were detected by Bultrasonography in 47 cases, 2 to 4 enlarged parathyroid glands in each case. Two cases had cervical CT scanning and two and three hyperplastic parathyroid glands were discovered respectively. All cases had hemodialysis three times per week and heparin-free hemodialysis was performed the day before operation. Forty-seven patients underwent intravenous ${ }^{99 \mathrm{~m}}$ Tc-MIBI 2 hours prior to surgery.

\section{Surgical procedure}

All patients were operated under supervision of one single surgeon. With the patients under anesthesia cervical plexus and neck hyperextended, a Kocher's incision is made, preferably in a skin crease. Tissues from skin to muscles were dissected layer by layer until the thyroid gland was exposed. Then the middle thyroid veins were cut off, and the thyroid gland was turned over medially. With the combination of preoperative ultrasonography, intraoperative exploration, and intraoperative gamma probe detection, all of the parathyroid tissues were carefully discovered and removed. The operation was performed carefully avoiding any damage to the parathyroid capsules. Resection of the surrounding fat tissue of original parathyroid glands is essential.

All removed tissues were intraoperatively verified by frozen section. Surgical pathology reports of parathyroid tissues removed were reviewed in all procedures performed at our hospital. The resected tissues were kept in sterilized iced saline. If fewer than four glands were found, then total parathyroidectomy without autotransplantation and transcervical thymectomy were undertaken. Thymectomy was not performed routinely if four parathyroid glands had been confidently identified. Diffuse-type hyperplastic parathyroid tissue(no nodular hyperplastic parathyroid tissue) was chosen for autografting. The estimated weight of the autograft tissue is $30 \mathrm{mg}$. After the strap muscles were closed, a $1.0 \mathrm{~cm}$ pocket was developed parallel to sternocleidomastoid muscle fibers. After it was certain that there was no bleeding in the muscle pocket, $30 \mathrm{mg}$ of parathyroid gland (cutting into pieces of $1 \mathrm{~mm}^{3}$ in size) without nodular hyperplasia was implanted into the muscular bed of the patients' sternocleidomastoid muscle. The muscle fibers anterior to the pocket containing the 
parathyroid tissue were then sutured closed with unabsorbable sutures, and the cephalad and caudad portions of the autograft site were marked with titanic clips for future reference, in case further reduction of functioning parathyroid tissue became necessary. Care was taken not to traumatize the area of the autograft during closure of the incision, in an effort to avert bleeding into the area that causing impaired revascularization of the parathyroid tissue.

Intraoperative PTH was performed trying to confirm total removal of the parathyroid glands, so as to avoid overlooking remaining or supernumerary glands. Peripheral venous blood sample $(5.0 \mathrm{~mL})$ was obtained immediately after induction of anesthesia and 30 minutes after removal of all parathyroid glands.

If the surgeon identifies 3 glands and cannot identify the 4th gland, or intraoperative PTH was greater than $400 \mathrm{ng} / \mathrm{L}$, complete cervical exploration of ectopic sites (explore retropharyngeal and esophageal spaces, trace recurrent laryngeal nerve into chest, open carotid sheath, and do not perform median sternotomy) and cervical thymectomy were performed $[11,12]$.

Three patients had undergone thyroidectomy additionally (one patient with papillary thyroid microcarcinoma and 2 cases with diffuse Hashimoto thyroiditis and large multinodular goiter).

Approximately $80 \mathrm{mg}$ of the parathyroid tissue will be placed in cold sterile saline solution (containing a solution of $80 \%$ culture media, $10 \%$ patient serum and $10 \%$ dimethyl sulfoxide) for later cryopreservation. The vial is then cooled to $-70^{\circ} \mathrm{C}$ at a decreasing rate of $1^{\circ} \mathrm{C}$ per minute.

\section{Postoperative management}

For the prevention of postoperative tetany, all patients received oral or intravenous calcium (higher dialysate Ca levels in 45 patients) if indicated. 45 patients were given calcium supplement postoperatively through a deep vein infusion pump to maintain adequate calcium levels. The serum calcium concentration was monitored every 12 hours to adjust the oral and/or intravenous calcium treatment. Calcium gluconate of 8-16 g per 24 hours was administered for one to two weeks, then, the rate and times of calcium infusion were adjusted according to the results of serum calcium measurement to maintain the serum concentration within the range of 1.8-2.3 $\mathrm{mmol} / \mathrm{L}$ and finally until the serum calcium was stabilized (usually in one to two weeks). Afterwards, oral calcium administration (calcium carbonate of 3-12 g per day) was prescribed. Meanwhile, postoperative oral Calcitriol was administrated with the dose of $0.25-2.5 \mu \mathrm{g}$ per day for one to three weeks, gradually diminished to 0.25-0.5 $\mathrm{gg}$ per day in total parathyroidectomy with autotransplantation group, and $0.75-1 \mu \mathrm{g}$ per day in total parathyroidectomy group.
Higher Ca dialysate is helpful to sustain normal serum Ca levels. Parathyroid hormone was measured postoperatively, and heparin-free hemodialysis was resumed for every patient, 24 hours postoperatively.

Patients were discharged when corrected calcium levels were above $2.0 \mathrm{mmol} / \mathrm{L}$ and free of hypocalcemic symptoms. Follow-up biochemical markers included serum phosphate, calcium, levels of 25-Hydroxyvitamin D3 (1,25-Hydroxyvitamin D3 is better, but now we are inaccessible of this test, will be included later) and PTH.

After discharge, a follow-up visits at 1, 3, 6, 12 months, and every six months thereafter are executed. Follow-up visits consist of telephone interview, in-clinic visits, direct mail, and email. A brief telephone questionnaire including follow-up medical records and biochemistry studies at local affiliated hemodialysis hospitals was used to evaluate patients' compliance with postoperative oral calcium, Calcitriol and symptom relief.

\section{Statistical analysis}

The continuous data were tested by the $t$-test, and categorical data were tested by the chi-square test or Fisher's exact test. The statistical software used was Social Sciences version 15.0. Differences were considered significant at $p$-value $<0.05$.

\section{Results}

One hundred and eighty-seven parathyroid glands identified at the initial operation were reported in 47 patients (Table 1). Thirty-three (35.1\%) inferior glands were located in the thymic tongue. 43 of the 47 patients had the diagnosis of parathyroid hyperplasia, four patients had a benign adenoma. 45 patients had 4 parathyroid glands (Figure 2). More than 4 glands were discovered only in one patient at the primary operation (Figure 3). Three glands were removed in 1 patient. After operation, pruritus, bone pain and muscle weakness disappeared, and serum PTH and serum phosphate were declined markedly (Table 2).

Of 47 cases, 45 had successful operation. 2 patients had persistent hyperparathyroidism in total parathyroidectomy group(one patient was found the 5th supernumerary gland in 1 year after the surgery, Figure 4). The detecting sensitivity combined with preoperative ${ }^{99 \mathrm{~m}}$ Tc-MIBI-SPECT scan, intraoperative gamma probe detection, intraoperative PTH assay, and intraoperative exploration for parathyroid glands was $95.7 \%$. No recurrent laryngeal nerve palsies were encountered. And there were no perioperative deaths. Complications were two cervical bleedings following postoperative hemodialysis which needed surgical intervention.

The duration of hospitalization was 10.5 days on average. Graft-dependent recurrence was not observed. 
Table 1 Demographics, symptoms, and preoperative or postoperative biochemistry

\begin{tabular}{|c|c|c|c|}
\hline Parameter & tPTX+AT Group $(n=14)$ & tPTX Group $(n=33)$ & $P$ Value \\
\hline Age, median (years) & $46.5 \pm 13.9(28-63)$ & $45.8 \pm 14.2(29-71)$ & $>0.05$ \\
\hline Men/women & $8 / 6$ & $18 / 15$ & $>0.05$ \\
\hline Duration of dialysis (years) & $9(3-19)$ & $8.8(3-17)$ & $>0.05$ \\
\hline Renal transplant (no.) & 2 & 5 & $>0.05$ \\
\hline Follow-up, mean (months) & $43.1 \pm 8.9(9-62)$ & $41.6 \pm 10.4(9-62)$ & $>0.05$ \\
\hline Preoperative BMD (Z-score) & $-3.72 \pm 1.12$ & $-3.66 \pm 0.98$ & $>0.05$ \\
\hline \multicolumn{4}{|l|}{ Symptoms } \\
\hline Fractures or bone pain (no.\%) & $14(100)$ & $33(100)$ & $>0.05$ \\
\hline Kidney stone (no.\%) & 0 & 0 & \\
\hline Pruritus (no.\%) & $12(85.7)$ & $30(90.9)$ & $>0.05$ \\
\hline Fatigue/weakness (no.\%) & $8(57.1)$ & $20(60.6)$ & $>0.05$ \\
\hline Osteoporosis (no.\%) & $13(92.8)$ & $32(96.9)$ & $>0.05$ \\
\hline \multicolumn{4}{|l|}{ Preoperative biochemistry } \\
\hline PTH (ng/L) & $2746 \pm 886(2430-3809)$ & $2798 \pm 983(1600-4280)$ & $>0.05$ \\
\hline $\mathrm{Ca}(\mathrm{mmol} / \mathrm{L})$ & $2.6 \pm 0.21(2.28-2.81)$ & $2.58 \pm 0.23(2.3-2.95)$ & $>0.05$ \\
\hline $\mathrm{P}(\mathrm{mmol} / \mathrm{L})$ & $2.5 \pm 0.73(1.75-3.91)$ & $2.52 \pm 0.82(1.77-4.31)$ & $>0.05$ \\
\hline 25(OH)D3(ng/ml) & $10.31 \pm 2.35$ & $10.45 \pm 2.41$ & $>0.05$ \\
\hline Postoperative 1st day biochemistry & & $(n=31)$ & \\
\hline PTH (ng/L) & $35.3 \pm 16.8$ & $16.8 \pm 7.5$ & $>0.01$ \\
\hline $\mathrm{Ca}(\mathrm{mmol} / \mathrm{L})$ & $1.92 \pm 0.38$ & $1.79 \pm 0.37$ & $>0.05$ \\
\hline $\mathrm{P}(\mathrm{mmol} / \mathrm{L})$ & $1.83 \pm 0.71$ & $1.76 \pm 0.68$ & $>0.05$ \\
\hline Symptoms relief (no.\%) & & $(n=31)$ & \\
\hline Bone pain (no.\%) & $14(100)$ & $31(100)$ & $<0.05$ \\
\hline Pruritus (no.\%) & $12(100)$ & $30(96.8)$ & $>0.05$ \\
\hline Postperative BMD (Z-score) & $-2.83 \pm 1.92$ & $-3.16 \pm 1.68$ & $>0.05$ \\
\hline Recurrence & 0 & 0 & $<0.05$ \\
\hline Postoperative symptomatic recurrent hypocalcemia & 0 & 2 & $<0.05$ \\
\hline Postoperative 6 months biochemistry & & $(n=31)$ & \\
\hline PTH (ng/L) & $13.69 \pm 6.29$ & $8.87 \pm 6.15$ & $<0.05$ \\
\hline $\mathrm{Ca}(\mathrm{mmol} / \mathrm{L})$ & $2.01 \pm 0.19$ & $1.91 \pm 0.21$ & $<0.05$ \\
\hline $\mathrm{P}(\mathrm{mmol} / \mathrm{L})$ & $0.895 \pm 0.18$ & $0.95 \pm 0.22$ & $<0.05$ \\
\hline 25(OH)D3 (ng/ml) & $16.36 \pm 2.67$ & $11.71 \pm 2.34$ & $<0.05$ \\
\hline
\end{tabular}

Abbreviations: $t P T X+A T$ total parathyroidectomy with autotransplantation, $t P T X$ total parathyroidectomy, BMD bone mineral density, PTH parathyroid hormone, 25 (OH)D3 25-Hydroxyvitamin $D_{3}$.

No evidence of clinical bone disease and pathological fractures detected after a mean observation period of 42 months (range: 9-62 months). After discharge, two patients (in total parathyroidectomy group) were readmitted because of postoperative symptomatic recurrent hypocalcemia (PTH:2.39 ng/L and $3.57 \mathrm{ng} / \mathrm{L})$. One patient who underwent kidney transplantation after total parathyroidectomy with trace amounts of parathyroid tissue autotransplantation did not develop serious hypocalcemia or osteomalacia. Rudimentary and split glands were not present in all cases.

\section{Discussion}

Chronic renal failure is a powerful stimulus for parathyroid cell proliferation. With the development of new technologies, the survival time of the haemodialysis patients is being obviously extended. SHPT is a severe and frequent complication in patients with advanced chronic kidney disease, characterized by hyperaplasia of all parathyroid glands and elevated serum PTH levels [13,14]. Parathyroidectomy is only used when all medical therapy (new therapeutic agents including vitamin D-receptor activators and calcium-mimetics, and new phosphate 


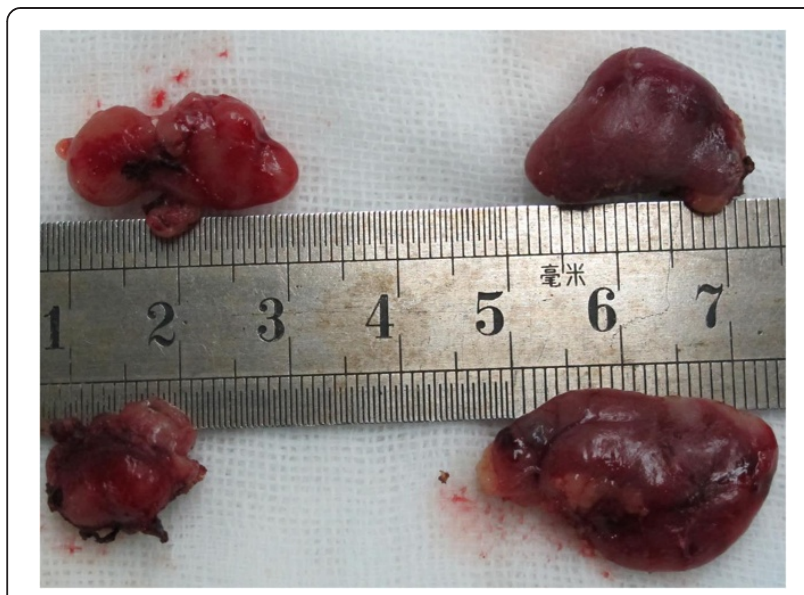

Figure 2 Four parathyroid glands identified at the primary operation in patient for secondary hyperparathyroidism.

binders) is unsuccessful [15]. In China, the prevalence rate of sHPT patients with parathyroidectomy indication is unknown. Furthermore, in recent years contradictions and disputes of physician-patient are increasingly intensified in China. It is thought that the access of sHPT patients to surgical treatment is limited and particularly restricted to university centers. Parathyroidectomy indication is practically unequivocal. According to our experience, the presence of extraskeletal calcification, calciphylaxis, debilitating bone disease, refractory pruritus, severe hypercalcemia, and PTH $>1600 \mathrm{ng} / \mathrm{L}$ are strong indications for surgical treatment.

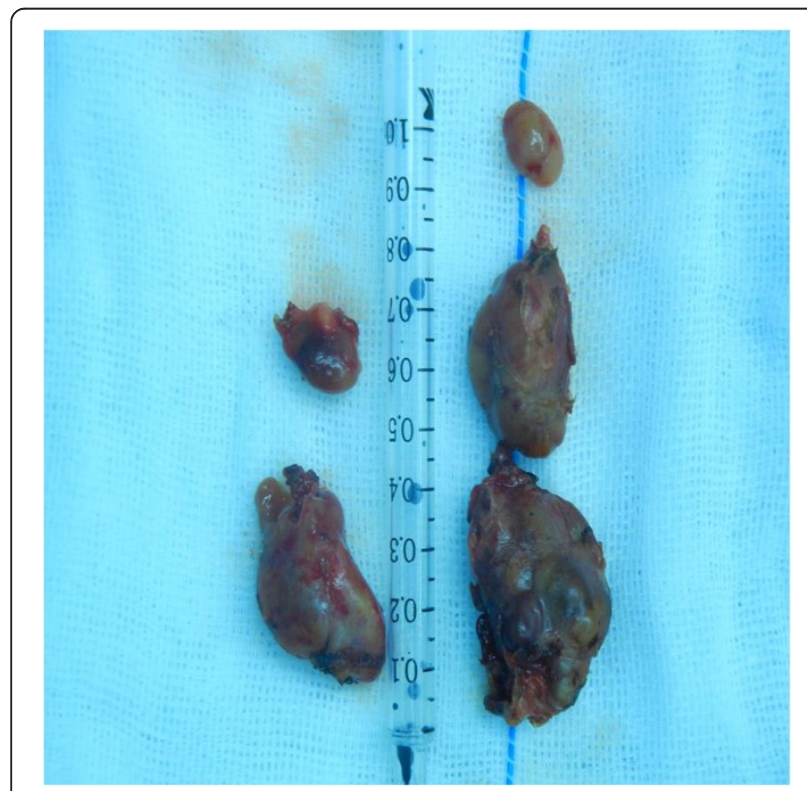

Figure 3 Five parathyroid glands identified at the primary operation in patient for secondary hyperparathyroidism.
The best surgical approach for renal hyperparathyroidism is yet to be determined and remains controversial in the literature. There are three accepted main types of surgical procedures and variations of these approaches (subtotal parathyroidectomy, total parathyroidectomy, and total parathyroidectomy with autotransplantation) $[15,16]$. Every procedure has its own disadvantages besides advantages. Sanbury [17] first described subtotal parathyroidectomy in 1960, the major defect of subtotal parathyroidectomy is that it is very difficult to recognize which gland is suitable for preservation by observation with naked eyes. This may cause recurrence of hyperparathyroidism. Once recurrence occurs, re-exploration of the neck is required, thus there is a greater risk of injuring the recurrent laryngeal nerves than at the initial operation, and reoperation also seems to introduce the risk of parathyromatosis.

Total parathyroidectomy and autotransplantation (the smallest gland was chosen) was first performed by Wells in 1975 [18]. Small amounts of resected parathyroid tissue can be autografted in the muscles of the forearm or neck, as well as in the subcutaneous tissue of the chest or abdomen. A randomized study suggested that total parathyroidectomy with autotransplantation had a lower rate of recurrent SHPT and an improved clinical outcome compared to subtotal parathyroidectomy. Reoperation was for persistent sHPT in 82 of 485 (17\%). Findings at reoperation included: autograft hyperplasia (49\%), supernumerary glands (20\%), remnant hyperplasia $(17 \%)$, a missed in situ gland (7\%), and a negative exploration (5\%). Reoperation determined that inadequate cervical explorations occurred in $42 \%$ of patients who had undergone a subtotal parathyroidectomy and in $34 \%$ of patients who had undergone a total parathyroidectomy with autotransplantation [14]. Tominaga who had the biggest series consisting of 2660 patients reported that graft-dependent recurrent sHPT was 248(9.3\%), and 216 (8.1\%) patients underwent only removal of the autograft and $32(1.2 \%)$ required both removal of the autograft and resection of residual parathyroid gland in the neck or mediastinum [19]. We thought that 30 pieces of $1 \times 1$ $\times 3 \mathrm{~mm}$ parathyroid tissue was more than $30 \mathrm{mg}$ for autografting. Operative failures occur because of the limitations in preoperative localization, inadequate exploration, and the natural history of hyperplastic parathyroid tissue. Although we were unable to identify the superiority of one operation over the other, operative success can be improved with an adequate cervical exploration. We believe sternocleidomastoid muscle is a better autografting area because of easy accessibility, one operative site, less graft ischemia, low incidence of infection, and high success rate due to excellent blood supply. But, sternocleido-mastoid muscle is not the standard site for autotransplantation in secondary hyperparathyroidism. In the 
Table 2187 parathyroid glands identified at the primary operation in 47 patients for secondary hyperparathyroidism

\begin{tabular}{llll}
\hline Located in behind the thyroid gland & No. of parathyroid glands & The size $(\mathbf{m m})$ & The volume $(\mathbf{m L})$ \\
\hline Right superior parathyroid gland & 47 & $5-22(9.1 \pm 4.1)$ & $0.5-2.2(0.9 \pm 0.4)$ \\
Right inferior parathyroid gland & 47 & $18-35(24 \pm 4.8)$ & $1.7-3.6(2.1 \pm 0.5)$ \\
Left superior parathyroid gland & 46 & $5-20(8.8 \pm 3.7)$ & $0.6-2.1(1.1 \pm 0.47)$ \\
Left inferior parathyroid gland & 47 & $15-33(21 \pm 4.9)$ & $1.6-3.5(2.2 \pm 0.8)$ \\
\hline
\end{tabular}

recurrent condition, ${ }^{99 m}$ Tc-MIBI-SPECT/CT $\operatorname{scan}(\mathrm{a}$ imaging modality that enabled reliable and precise localization of the parathyroid) is able to distinguish between a cervical recurrence and a graft depending recurrence. Diffuse-type hyperplastic parathyroid tissue preferably was chosen for autografting to prevent recurrent SHPT. Recurrent HPT after total parathyroidectomy with autotransplantation is usually due to overgrowth of the autograft. We consider thirty pieces of $1 \times 1 \times 3 \mathrm{~mm}$ parathyroid tissue (about 100 micrograms) too much. Ten pieces of $1 \times 1 \times 3 \mathrm{~mm}$ parathyroid tissue (about 30 micrograms) is enough. For patients who demand longterm hemodialysis after parathyroidectomy, the risk of recurrence is not negligible. Thus, to avoid recurrent HPT, all parathyroids, including supernumerary glands, should be identified. In our series, $35.1 \%$ of inferior glands were located in the thymic tongue. If the surgeon cannot identify 4 glands, removal of thymic tissue from the neck incision is essential to avoid missing glands. Most patients underwent artificial arteriovenous fistula in bilateral forearms for hemodialysis. We believe it would be easier and safer to remove residual parathyroid tissue from sternocleidomastoid muscle at recurrence as

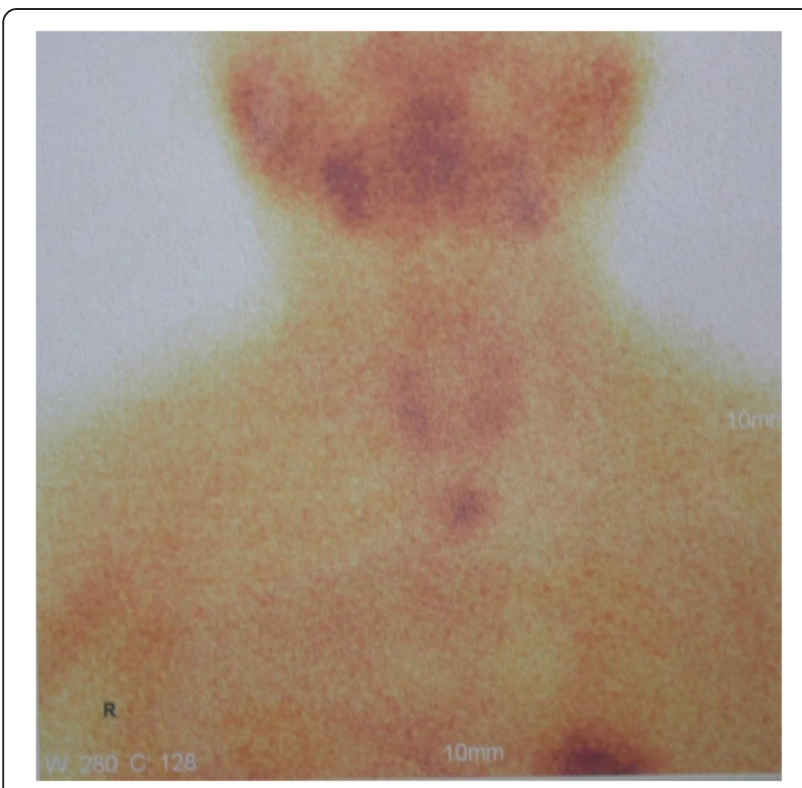

Figure 4 The $5^{\text {th }}$ parathyroid gland was confirmed by positive sestamibi ${ }^{99} \mathrm{~m} \mathrm{Tc}$ investigation in the mediastinum in 1 year after the surgery. compared to from the forearm. Reoperation may be relatively simple for recurrent hyperparathyroidism induced by the hyperfunction of autografted parathyroid tissue, because surgical access to sternocleidomastoid muscle is simple, and it does not require general anesthesia, also avoid the risk of major surgical complications such as laryngeal nerve injury.

In order to suppress parathyroid secretion completely and reduce recurrent hyperparathyroidism, total parathyroidectomy without autotransplantation was performed in 1967 [20]. Patients who had total parathyroidectomy without autotransplantation had temporary hypocalcemia postoperatively and became asymptomatic, despite hypocalcemia, when they were supplemented with calcitriol in the long term. After all types of surgery, attention must be kept on patients' postoperative period. The lack of osteoclastic activity caused by a decrease in PTH postoperatively may lead to a precipitous fall in calcium levels, a condition called "hungry-bone syndrome" [21]. While the autographed parathyroid tissue begins to function in two to three weeks, patients may have severe hungry bone syndrome in this period. It is necessary that all patients received calcium and calcitriol supplement for low calcium levels.

The function of the grafted tissue can be followed in most patients by the determination of the PTH concentration. In 14 of our cases we perform trace amounts of parathyroid tissue $(30 \mathrm{mg})$ autotransplantation and in follow-up (9-62 months) no recurrence observed. The sPTH level has been used to evaluate the results of parathyroidectomy. Ideally, the completeness of the operation could be biochemically confirmed by utilizing the intraoperative PTH assay. If intraoperative PTH is more than $400 \mathrm{ng} / \mathrm{L}$, supernumerary parathyroid gland may not be completely resected. The extent of operative exploration for supernumerary glands may become less controversial with widespread utilization of the intraoperative PTH assay as an adjunct in guiding the completeness of resection. The utilization of intraoperative PTH monitoring may become a useful adjunct for assuring that the patient has undergone an adequate parathyroidectomy in sHPT [22-26]. Patients whose PTH level dropped under $400 \mathrm{ng} / \mathrm{L}$ by the removal of parathyroid gland, sHPT could be controlled by medical treatment after the operation. Patients who underwent total parathyroidectomy without autotransplantationusually had 
almost untraceable sPTH levels immediately after surgery, but later it can be detected again. The rise in serum PTH may be a result of parathyroid cell re-proliferation stimulated by hypocalcemia in these patients. A similar biochemical rebounding tendency was observed. In our study, clinical symptom relief has no statistical difference between total parathyroidectomy with trace amounts of parathyroid tissue autotransplantation group and total parathyroidectomy group. Bone pain disappeared in almost all patients within 1 week after surgery. Total parathyroidectomy without autotransplantation leads to harmful definitive hypoparathyroidism condition. Clinical experience showed that total parathyroidectom had disadvantages, such as candidate for kidney transplantation, lifelong substitution therapy, and osteopenia developed in the absence of PTH $[6,15,26,27]$.

\section{Conclusions}

The total parathyroidectomy with trace amounts of parathyroid tissue autotransplantation is a feasible, safe and effective surgical option for the patients with sHPT.

\section{Competing interests}

The authors declare that they have no competing interests.

\section{Authors' contributions}

$\mathrm{QH}$ had operated cases and analyzed all data. DZ, LZ and ZF participated in the design of the study and performed the statistical analysis. PZ, JZ, SD,YL, YG, ZL,and LC did the assistant of the operation. All authors read and approved the final manuscript.

\section{Acknowledgments}

This work was supported by the Third Batch Special Foundation of China Postdoctoral Science Foundation (No. 201003759) and the President Funding of Jinan Military General Hospital of PLA (No. 2011 M 03). We appreciated the help on statistics in this article given by Fei He, Ph.D student in the Department of Applied Mathematics and Statistics of the State University of New York at Stony Brook.

\section{Statement}

Corresponding author had obtained permission from the copyright holder to reproduce the figure, and confirmed that consent to publish the Figure 1 by the patient

\section{Author details}

'Department of Thyroid and Breast Surgery, Jinan Military General Hospital of PLA, No.25 Shifan Road, Jinan 250031, People's Republic of China. ${ }^{2}$ Blood Purification Center, Jinan Military General Hospital of PLA, Jinan 250031, People's Republic of China.

Received: 27 April 2013 Accepted: 25 April 2014

Published: 5 May 2014

\section{References}

1. Schneider R, Kolios G, Koch BM, Fernández ED, Bartsch DK, Schlosser K. An economic comparison of surgical and medical therapy in patients with secondary hyperparathyroidism-the German perspective. Surgery 2010, 148(6):1091-1099.

2. lannazzo S, Carsi M, Chiroli S: A cost-utility analysis of cinacalcet in secondary hyperparathyroidism in five European countries. Appl Health Econ Health Policy 2012, 10(2):127-138.

3. Shen WT, Kebebew E, Suh I, Duh QY, Clark OH: Two hundred and two consecutive operations for secondary hyperparathyroidism: has medical management changed the profiles of patients requiring parathyroidectomy? Surgery 2009, 146(2):296-299.
4. Conzo G, Perna AF, Savica V, Palazzo A, Della Pietra C, Ingrosso D, Satta E, Capasso G, Santini L, Docimo G: Impact of parathyroidectomy on cardiovascular outcomes and survival in chronic hemodialysis patients with secondary hyperparathyroidism. A retrospective study of 50 cases prior to the calcimimetics era. BMC Surg 2013, 13(Suppl 2):S4. doi:10.1186/ 1471-2482-13-S2-S4.

5. Kovacevic B, Ignjatovic M, Zivaljevic V, Cuk V, Scepanovic M, Petrovic Z, Paunovic I: Parathyroidectomy for the attainment of NKF-K/DOQ $I^{\mathrm{TM}}$ and KDIGO recommended values for bone and mineral metabolism in dialysis patients with uncontrollable secondary hyperparathyroidism. Langenbecks Arch Surg 2012, 397(3):413-420.

6. Naranda J, Ekart R, Pečovnik-Balon B: Total parathyroidectomy with forearm autotransplantation as the treatment of choice for secondary hyperparathyroidism. J Int Med Res 2011, 39(3):978-987.

7. Schneider R, Slater EP, Karakas E, Bartsch DK, Schlosser K: Initial parathyroid surgery in 606 patients with renal hyperparathyroidism. World J Surg 2012, 36(2):318-326.

8. Sharma J, Raggi P, Kutner N, Bailey J, Zhang R, Huang Y, Herzog CA, Weber C Improved long-term survival of dialysis patients after near-total parathyroidectomy. J Am Coll Surg 2012, 214(4):400-408.

9. Conzo G, Perna AF, Sinisi AA, Palazzo A, Stanzione F, Della Pietra C, Livrea A: Total parathyroidectomy without autotransplantation in the surgical treatment of secondary hyperparathyroidism of chronic kidney disease. J Endocrinol Invest 2012, 35(1):8-13.

10. Madorin C, Owen RP, Fraser WD, Pellitteri PK, Radbill B, Rinaldo A, Seethala RR, Shaha AR, Silver CE, Suh MY, Weinstein B, Ferlito A: The surgical management of renal hyperparathyroidism. Eur Arch Otorhinolaryngol 2012, 269(6):1565-1576.

11. Schneider R, Waldmann J, Ramaswamy A, Fernández ED, Bartsch DK, Schlosser K: Frequency of ectopic and supernumerary intrathymic parathyroid glands in patients with renal hyperparathyroidism: analysis of 461 patients undergoing initial parathyroidectomy with bilateral cervical thymectomy. World J Surg 2011, 35(6):1260-1265.

12. Uludag $M$, Yetkin G, Citgez B, Ozguven BY, Cengiz AN, Ozsahin H, Isgor A: The role of cervical thymectomy in surgical treatment of secondary hyperparathyroidism. Bratis/ Lek Listy 2011, 112(7):385-389.

13. Yuan CM, Nee R, Narayan R, Abbott KC: Treatment of secondary hyperparathyroidism with parathyroidectomy instead of cinacalcet: time to pick the low-hanging fruit ? Am J Kidney Dis 2012, 60(2):179-181.

14. Alesina PF, Hinrichs J, Kribben A, Walz MK: Minimally invasive video-assisted parathyroidectomy (MIVAP) for secondary hyperparathyroidism: report of initial experience. Am J Surg 2010, 199(6):851-855.

15. Drakopoulos S, Koukoulaki M, Apostolou T, Pistolas D, Balaska K, Gavriil S, Hadjiconstantinou V: Total parathyroidectomy without autotransplantation in dialysis patients and renal transplant recipients, long-term follow-up evaluation. Am J Surg 2009, 198(2):178-183.

16. Iwamoto N, Sato N, Nishida M, Hashimoto T, Kobayashi H, Yamasaki S, Ono T, Nishimura M, Tokoro T, Sakoda C, Murakawa M, Okino K, Okamoto Y, Imai R, Adachi N, Ninomiya K, Mabuchi H, Koyama M, Nakanouchi T, Iseki K: Total parathyroidectomy improves survival of hemodialysis patients with secondary hyperparathyroidism. J Nephrol 2012, 25(5):755-763.

17. Sanbury SW, Lumb GA, Nicholson WF: Elective subtotal parathyroidectomy for renal hyperparathyroidism. Lancet 1960, 1(7128):793-799.

18. Wells SA Jr, Gunnells JC, Shelburne JD, Schneider AB, Sherwood LM: Transplantation of the parathyroid glands in man: clinical indications and results. Surgery 1975, 78(1):34-44.

19. Tominaga Y, Matsuoka S, Uno N, Tsuzuki T, Hiramitsu T, Goto N, Nagasaka T, Watarai $Y$, Uchida K: Removal of autografted parathyroid tissue for recurrent renal hyperparathyroidism in hemodialysis patients. World $J$ surg 2010, 34(6):1312-1317.

20. Ogg CS: Total parathyroidectomy in treatment of secondary (renal) hyperparathyroidism. Br Med J 1967, 4(5575):331-334.

21. Goldfarb M, Gondek SS, Lim SM, Farra JC, Nose V, Lew Jl: Postoperative hungry bone syndrome in patients with secondary hyperparathyroidism of renal origin. World J Surg 2012, 36(6):1314-1319.

22. Chan HW, Chu KH, Fung SK, Tang HL, Lee W, Cheuk A, Yim KF, Tong MK, Lee KC: Prospective study on dialysis patients after total parathyroidectomy without autoimplant. Nephrology (Carlton) 2010, 15(4):441-447.

23. Yan H, Sharma J, Weber CJ, Guyton RA, Perez S, Thourani VH: Elevated parathyroid hormone predicts mortality in dialysis patients undergoing valve surgery. Surgery 2011, 150(6):1095-1101. 
24. Kim WY, Lee JB, Kim HY: Efficacy of intraoperative parathyroid hormone monitoring to predict success of parathyroidectomy for secondary hyperparathyroidism. J Korean Surg Soc 2012, 83(1):1-6.

25. Puccini M, Carpi A, Cupisti A, Caprioli R, lacconi P, Barsotti M, Buccianti P, Mechanick J, Nicolini A, Miccoli P: Total parathyroidectomy without autotransplantation for the treatment of secondary hyperparathyroidism associated with chronic kidney disease: clinical and laboratory long-term follow-up. Biomed Pharmacother 2010, 64(5):359-362.

26. Agha A, Loss M, Schlitt HJ, Scherer MN: Recurrence of secondary hyperparathyroidism in patients after total parathyroidectomy with autotransplantation: technical and therapeutic aspects. Eur Arch Otorhinolaryngol 2012, 269(5):1519-1525.

27. Conzo G, Perna A, Candela G, Palazzo A, Parmeggiani D, Napolitano S, Esposito D, Cavallo F, Docimo G, Santini L: Long-term outcomes following "presumed" total parathyroidectomy for secondary hyperparathyroidism of chronic kidney disease. G Chir 2012, 33(11-12):379-382.

doi:10.1186/1471-2482-14-26

Cite this article as: He et al:: Total parathyroidectomy with trace

amounts of parathyroid tissue autotransplantation as the treatment of choice for secondary hyperparathyroidism: a single-center experience. BMC Surgery 2014 14:26.

\section{Submit your next manuscript to BioMed Central and take full advantage of:}

- Convenient online submission

- Thorough peer review

- No space constraints or color figure charges

- Immediate publication on acceptance

- Inclusion in PubMed, CAS, Scopus and Google Scholar

- Research which is freely available for redistribution 